\title{
Canlı Yayın Platformlarında Ürün Marka Uygulamaları
}

DOI: $10.26466 /$ opus.738697

*

İkram Daștan*

* Doç. Dr, Yalova Üniversitesi, İktisadi ve İdari Bilimler Fak., İşletme Bölümü Yalova/ Türkiye E-Posta: ikram.dastan@yalova.edu.tr

ORCID: $0000-0002-4366-8698$

Öz

Yeni bir iletişim kanalı olarak sosyal medya platformlarında canlı yayınlar gün geçtikçe popüler hale gelmektedir. Bu durumu fark eden işletmeler bu ortamları etkin bir şekilde kullanmaya başlanmış, canlı yayınlarda çeşitli ürün yerleştirmeler, ünlüler veya popüler kullanıcılar aracıllğ̆ıyla ürün ve marka tanıtımları gerçekleştirmeye başlamışlardır. Araştırmada sosyal medya üzerinden yapılan canlı yayınların kullanım amacı, önemi, bireylere ve işletmelere olan etkisi, kullanım sıklıkları ele alınmış ve elde edilen bulgular değerlendirilmiştir. Araştırma kapsamında canlı yayın platformlarından biri seçilerek 15 gün boyunca belirli aralıklarla günlük 10 izleme gerçekleştirilmiş. Çeşitli kriterler göz önünde bulundurularak kodlamalarla izlemeler elektronik ortama aktarllmıştır. Toplamda 280 izleme gerçekleştirilmiştir. Ayrıca aynı platform kullanılarak 2015 ve 2017 yıllar için ayrı ayrı izlemeler yapılarak kullanıcıların zaman içinde platformlara olan ilgisi ve geçirdiği zamanlar belirlenmiştir. Elde edilen bulgular sonucunda yillar itibariyle bu platformlarda izleyici sayısının arttığı, üst strlardaki yayınların daha fazla dikkat çektiği, belli gün ve saatlerde yapılan yayınların daha etkin olduğu, yayınların yaklaşık olarak \% 50'sinde ürün tanıtımı ve reklamı olduğu tespit edilmiştir.

Anahtar Kelimeler: Sosyal Medya, Canlı Yayın Platformları, Sosyal Medyada Ürün ve Marka Tanttımi, Periscope, Canlı Yayın 


\title{
Product / Brand Placements on Live Broadcasting Applications
}

\begin{abstract}
As a new communication channel live broadcastings have been more popular on social media platforms day by day. After the awareness of this popularity, the companies have started to use these channels more effectively such as placing products and brands on live broadcasts, promoting products and brands via celebrities and micro-celebrities. The aim of this study is to reveal the motivation and importance to watch live broadcasts on social media and to explore its effects on individuals and companies. Data was collected through a live broadcasting application and randomly selected broadcasts were watched 10 times in a day during 15 days. Totally 280 broadcasts were watched and the videos were analyzed based on previously determined criteria. These study were applied both in 2015 and 2017 to reveal the differences in time. The results of the indicated that the number audiences of live broadcasts have increased in time, the broadcasts located at the top are watched more, the day of the week and time of the broadcasts affect the numbers of the audience and approximately $50 \%$ of the broadcasts include product / brand placement. In this study, it is aimed to scale university students' leisure time activities. In addition, it was studied to determine the order of preference of leisure time activities by scaling according to students gender, class, location type and socioeconomic level variables. $64.2 \%$ of respondents $(N=936)$ were female, $35.8 \%(N=521)$ were composed of male students. The data collection tool which has been specifically developed for this study by the researchers.
\end{abstract}

Keywords: Social Media, Live Broadcasting Platforms, Product Placement, Brand Placement, Periscope, Live Streaming 


\section{Giriş}

İnternetin yaygınlaşmaya başlaması ve gelişmesi ile hayatımıza giren sosyal medya, gün geçtikçe bireyler ve işletmeler için daha da vazgeçilmez hale gelmektedir. İlk olarak web 1.0 ile karşımıza çıkan internet html tabanlı statik salt okunur ve tek yönlü bir yapıya sahipti (O'Reilly, 2005; Goodchild, 2007) insanlar tek taraflı alıcı durumundaydı ve profesyonel unsurlar tarafından oluşturulan, paketlenen ve yayınlanan bilgi ve medyayı pasif olarak tüketmekteydiler (Livingstone, 2005). Akabinde, dinamik yapı sağlayan ve iki yönlü iletişimi sağlayan Web 2.0 teknolojileri (Robinson, 2007), yeni bir dijital teknoloji çağını başlatmıştır. Bu teknolojilerin ana çıktısını sosyal medya oluşturmuştur. Sosyal medya, "Web 2.0'in ideolojik ve teknolojik temellerini temel alan ve kullanıcı tarafından meydana getirilen içeriğin oluşturulmasına ve değiştirilmesine izin veren internet tabanlı bir grup uygulama" olarak tanımlanmaktadır (Kaplan ve Haenlein, 2010, s.61).

Sosyal medya, sosyal paylaşım siteleri (facebook, vkontakte gibi), mikro blog siteleri (twitter gibi), medya paylaşım siteleri (youtube, vine gibi), bookmarking siteleri, forumlar, bloglar, sanal dünyalar, ticaret toplulukları, vb. sosyal ağ uygulamalarını içerir (Mangold ve Faulds, 2009). Sosyal medya araçları ve kullanım türleri günden güne artmıştır. Facebook ve Youtube'un aylık kullanıcı sayısı 3 milyara ulaşmıştır (Webrazzi, 2018). Twitterin aylık aktif kullanıcı sayısı 320 milyona ulaşmış atılan tweet sayısı ise 500 milyonu geçmiştir (Socialbakers, 2018).

Öte yandan, sosyal medya araçları kişisel bilgileri yayınlamak için yeni olanaklar sunmakta ve milyonlarca kullanıcı sosyal medya alanlarında kendileriyle ilgili bilgileri açıklamaktadırlar. (Bazarova and Choi, 2014). Ancak çevrimiçi açıklamalarla klasik çevrimdışı açıklamalar arasında farklılıklar vardır. İnsanların sosyal medya sitelerinde paylaşmış olduğu içerik arkadaşları, takipçileri, tanıdıkları ve hatta yabancılar tarafından görülebilir (Bazarova and Choi, 2014). Günden güne yeni sosyal medya araçları yeni özellikler ile bu mecralarda yerini almaktadır. Bu mecralarda en önemli adımlardan biri ise çevrimiçi anında canlı yayın yapabilme özelliğidir (Bajarin 2015). 2014 yılında Kayvon Beykpour ve Joe Bernstein tarafından kurulan Periscope, en popüler ve büyüyen gerçek zamanlı video yayını uygulaması oldu. Dünyayı, başkalarının gözüyle gerçek zamanlı olarak keşfetmek sloganıyla yola çıkan Periscope'nin popülaritesi ve özellikleri sosyal medya 
sektöründe önemli aktörlerin dikkatini çekti; ve sonunda Twitter Periscope'u satın aldı. Periskop'un kurulmasının ardındaki fikir, 2013 yılında Kayvon Beykpour'un İstanbul'da Taksim'de gerçekleşen gezi olaylarını anlık olarak yayınlama ve insanların bu yayınları canlı izleyebilme isteğiyle ortaya çıtı. Beykpour'un fikrine paralel olan Periscope'un amacı dünyayı başkasının gözünden keşfetmek olmuştur (Periscope, 2015).

Gerçek zamanlı canlı yayın platformları henüz yeni olmasına rağmen, ünlüler, politikacılar, blogcular ve şirketler bu alanları çok aktif olarak kullanmaya başlamışlardır (Reilly, 2015; Bajarin, 2015). Örneğin, en popüler çevrimiçi kişiliklerden biri olan Katy Perry, Epix konser filmini takipçilerine anında yayınlamak için Periscope'u kullandı (Reilly, 2015). Ek olarak, Spotify bazı sahne arkası videolarını Periscope aracılığıyla yayınlamıştır benzer şekilde Red Bull Konuk evinde gerçekleşen etkinlikleri canlı olarak yayınlamıştır, DKNY, modayı takip edenler için moda hakkında anlık videolar yayınlamaktadır. Periscope ugulaması bir yılını doldurduğunda 200 milyon yayına ev sahipliği yapmıştı (Reuters, 2015). Canlı deneyimin özellikle genç kuşaklar tarafından daha otantik olarak görülmesi nedeniyle genç kuşaklar üzerinde daha hizlı yayılmasına neden olmuştur (Pophal, 2016). Ayrıca, blogerlar Periscope'u kullanarak aktif ve etkili bir şekilde çalışmaktadırlar. Seyahat Blogerları, seyahat ettikleri yerlerden gerçek zamanlı yayın yapmaya başlamışlardır. Yine benzer şekilde yemek blogerları alışveriş, yemek ve yemek deneyimleri hakkında yayın yapmaktadırlar (Bajarin, 2015). Kendiliğinden ve filtresiz görüşlere olan ilgi gittikçe artmakla beraber (Anderson, 2018). Öte yandan, gerçek zamanlı video akışı sağlayan platformların kullanımı bazı yasadışı durumlara ve gizlilik sorunlarına neden olmaktadır. Kullanıcılar ödemeli TV kanalları tarafından sunulan bazı spor oyunları, filmler, TV dizileri, özel şovları anında canlı olarak yayınlayabilmektedirler (ADWEEK, 2015; Bajarin, 2015). Yakın gelecekte, 5G teknolojileri, daha güçlü Wi-Fi bağlantıları ve geliştirilmiş akıllı telefonlar ve uygulamalar ile gerçek zamanlı video akışı araçları hem şirketler hem de kullanıcılar için daha güçlü araçlar haline geleceklerdir (Bajarin, 2015).

\section{Kuramsal Çerçeve}

Katz, Blumler ve Gurevitch (1974), kullanımlar ve doyumlar teorisinin odak noktasını "kitle iletişim araçlarının veya diğer kaynakların beklentilerini 
oluşturan, ihtiyaç duyulan sosyal ve psikolojik kökenler" olarak tanımlamışlardır (Rubin, 1998). Kullanımlar ve doyumlar teorisi, kullanıcıların ihtiyaç ve isteklerini karşılamak için medya araçlarını ve diğer iletişim formlarını nasıl kullandıklarına odaklanmaktadır (Rubin, 2002). Bu teori ilk olarak 1940'larda Radyo aracının etkinliğini ortaya çıarmak için geliştirilmiştir (Luo, 2002). Daha sonraları TV gibi diğer kitle iletişim araçlarına uygulanmıştır (Dunne ve diğerleri, 2010; Luo, 2002). Örneğin, Rubin (1994), televizyon programlarının bilgi edinme, kaçış, duygusal serbestlik, arkadaşlık, gerçeklik araştırması ve değer pekiştirme gibi birçok ihtiyacı karşılamak için izleyici tarafından izlendiğini ortaya koymuştur. Newhagen ve Rafaeli (1996), kullanımlar ve doyumlar teorisinin, çevrimiçi medya araçlarına uygun olabileceğini ileri sürmüşlerdir ve daha sonra çeşitli yazarlar, internet ve diğer sosyal medya araçlarını kullanmanın nedenlerini analiz etmek için bu teoriyi uygulamıştır.

Daha sonra, iternet ve sosyal medya araçları bağlamında kullanımlar ve doyumlar Teorisinin boyutlarını ortaya koymak için çeşitli çalışmalar yapılmıştır. Örneğin; Dunne, Lawyor ve Rowley (2010) bu teoriyi İletişim, Arkadaşlık, Eğlence, Kaçakçılık ve Bilgi konularında sosyal paylaşım siteleri üzerinde uyguladılar. Urista, Dong ve Day (2009), genç yetişkinlerin neden kullanımlar ve doyumlar teorisine göre sosyal ağ sitelerini kullandıklarını araştırmışlardır. Araştırma verimli iletişim, uygun iletişim, başkaları hakkında merak, popülerlik, ilişki oluşumu ve pekiştirme konularında gerçekleşmiştir. Haridakis ve Hanson (2009) çevrimiçi video izleme nedenlerini bulmak için kullanımlar ve doyumlar teorisini uygulamışlar ve katılımcıların eğlence, birlikte çalışma ve sosyal etkileşim için videolar aradıkları ve izledikleri sonucuna ulaşmışlardır. Kullanımlar ve doyumlar teorisinin sosyal medya araçları üzerine uygulanması ile ilgili diğer çalışmalar Tablo-1'de verilmektedir.

Tablo 1. Internet araçları ile kullanımlar ve doyumlar teorisi üzerine çalışmalar

\begin{tabular}{lll}
\hline Starkman & 2007 & Rahatlama, eğlence, teşvik \\
\hline Stafford and Gonier & 2004 & $\begin{array}{l}\text { Web arama, bilgi edinme, kişilerarası } \\
\text { iletişimde bulunma yeteneği ve sosyalleşme }\end{array}$ \\
\hline Matsuba & 2006 & Bilgi, kişilerarası iletişim ve eğlence \\
\hline Sheldon & 2008 & İlişkiler, zaman ve eğlence \\
\hline Raache and Raache & 2008 & $\begin{array}{l}\text { Yeni arkadaşlar edinme, arkadaşlarla iletişim kurma, } \\
\text { resimlere / fotoğraflara bakma }\end{array}$ \\
\hline Luo & 2002 & Enformatik, Eğlence \\
\hline
\end{tabular}


Daha önce de belirtildiği gibi, yeni özellikler sağlayan gerçek zamanlı video akışı araçları, en umut verici yeni medya iletişim araçlarından biri olarak kabul edilmektedir. Bu araçların kullanımı sadece giriş aşamasında olduğu için, bu araçları kullanmanın nedenleri kullanımlar ve doyumlar teorisi bağlamında gerçek zamanlı video akışı araçları kullanılarak hangi ihtiyaçların karşılandığıyla ilgili herhangi bir çalışma yapılmamıştır. Kullanımlar ve doyumlar teorisini, gerçek zamanlı video akışı araçlarını kullanmaya yönelik motivasyonları ortaya çıkarmak için uygulanmalı ve bu bağlamda teorinin varsayımları değerlendirilmelidir.

Akıllı telefonların yaygınlaşması geleneksel video tüketme yöntemlerini değiştirmektedir. Popülerlikteki bu büyümenin kanıtı, canlı akış platformlarındaki artış, kişi hikayeleri Facebook yayınlarında ve Twitter akışlarında belirgin bir video artışı gösterilebilir (Malik, 2015)

Birinin deneyimini paylaşmak, sosyal medya uygulamaları için yeni bir kavram değildir. YouTube, 2005'te başladığ günden bu yana kullanıcılara video oluşturma ve paylaşma platformu sunmaktadır. Vine, 2016 sonlarında kapatılmadan önce, kullanıcıların sosyal medya 6'lı videoları paylaştıkları son derece popüler bir uygulama olmuştu. Video paylaşma özelliğinin, sosyal medya kullanıcıları tarafından hızlı bir şekilde benimsemesiyle birlikte internet üstünde paylaşılan video içeriğin büyük bir kısmı sosyal platformlar aracılığıyla artmaya devam etmektedir. İnternet trafiğinin yüzde 80'inin 2019'a kadar video şeklinde olacağı tahmin edilmektedir (Savage, 2015).

Canlı yayın, genellikle gerçek zamanlı oyun oynama, özel etkinlikler ve sahne arkası turları gibi yaratıcı etkinliklerden oluşan ses ve video içeriğinin açık bir şekilde yayınlanmasını içerir (Todd ve Melancon 2018). Bu yayınlarda yayıncı, canlı yayın yaparak canlı metin sohbeti aracllı̆̆ıyla yanıt verebilen izleyicilerle iletişim kurabilir. İzleyici kitlesi, bir izleyici kadar küçük olabilir, ancak bugüne kadar en çok izlenen canlı akışlı video, 47 milyon toplam canlı görüntü almıştır (Spangler, 2016). Canlı yayın yapan yayıncılar, içerik oluşturucu ile tüketici arasında gerçek zamanlı interaktif bir deneyim sunarlar (Sjoblom ve Hamari, 2016). Bu açıdan bakıldığında pazarlamacılar ve reklam verenler giderek değişen, karmaşık bir ortamla karşı karşıya kalmışlardır (Philip ve Noble, 2007). Teknolojideki gelişmeler, güvenilir ve hızlı internet bağlantısının yaygınlaşması, yeni tüketici ilişki biçimleri için sürekli genişleyen küresel bir firsat doğurmuştur. Yapılan araştırmalarda araştır- 
macılar, bu süreçte tüketici katılımının önemini vurgulayarak tüketicilerin, genellikle çevrimiçi topluluklardan elde ettiği mesajları geleneksel medyadan elde edilenlerde daha güvenilir olarak göreceklerini belirttiler (Bae and Lee, 2011). Tüketici etkileşimi adına canlı yayın alanları hızlı bir şekilde artmaktadır. Dijital sektörde, Canlı yayın, video pazarlama ve video reklamc1lığa yönelik harcamaların 2019 yılına kadar yıllık 14 milyar doların üzerine çıkacağı öngörülmektedir (Gehlen, 2015; Facebook Live İstatistikler, 2017). $\mathrm{Bu}$ durum tüketicilerin sosyal medya platformlarında canlı olarak yayınladıkları video yayınlarının sayısının fazlalığından kaynaklanmaktadır. Videonun organik erişimi, statik fotoğraf gönderilerinden yüzde 135 daha yüksektir (Savage, 2016).

Canlı yayın platformlarının Facebook, Twitter, Instagram ve YouTube gibi mevcut sosyal medya devlerine entegrasyonu, bu platformun popülaritesini artırmaktadır. Sadece Facebook günde sekiz milyar video izleyiciye sahiptir ve Facebook'taki canlı videolar, canlı olmayanlardan üç kat daha uzun görüntülenmektedir (Savage, 2016). Sosyal medya pazarlama sektörünün yıllık raporunda, pazarlamacıların yüzde 60'ının video kullandığını, pazarlamacıların yüzde 75'inin videoların pazarlamada kullanımı hakkında daha fazla bilgi edinmek istediğini ve video kullanımını artırmayı planladığ1 tespit edilmiştir (Stelzner, 2016). Ayrıca, canlı yayın platformları özellikle pazarlamacılar tarafından yeni bir içerik dağıtım mekanizması olarak ilgi görmektedir. Pazarlamacıların yüzde 14'ü şu anda canlı yayın platformlarını kullanıor, pazarlamacıların yüzde 50'si gelecek yıl canlı yayın platformlarını kullanmayı planlıyor ve yüzde 50'si canlı yayın platformları hakkında daha fazla bilgi edinmek istemektedir (Stelzner, 2016).

Kullanıcıların metinsel içeriklerden ziyade haraketli ve video içeriklere daha fazla ilgili olduğu araştırmacılar tarafından ifade edilmektedir. Pazarlama faaliyeti yürüten işletmeler vermek istedikleri mesajı, yazılı olarak vermek yerine anlık olarak bu ortamlardan paylaşmayı önemli görmektedirler. Sosyal medya uygulamalarında canlı yayın yapan popülaritesi yüksek olan kullanıcılar ile iletişim kurabilen firmalar, kullanıcıların yapmış oldukları bu canlı yayınlarda farklı pazarlama politikaları ve farklı stratejiler kullanarak firmaya avantaj sağlamak istemektedirler. Sosyal medya uygulamalarında canlı yayınların yirmi dört saat erişilebilir olması, satın alma konusunda fikir oluşturması, etkileşimli olması, maliyetinin az olması, kitleyi takip etme ve yakından tanıma firsatı vermesi bilgi toplama ve fiyat 
karşılaştırabilme yapabilmesi, interaktif ve hızlı olma özelliği ile bireyler ve işletmeler açısından avantaj oluşturduğu ifade edilir.

Ünlü veya tanınmış kullanıcıların yayınlarına katılan bireyler, yayın sırasında yayını yapan kullanıcının kullandığı bir ürüne dikkat edip bu ürünü kullanmaya yönelebilir, yayını yapan kullanıcının tavsiye edeceği bir ürünü ya da hizmeti dikkate değer bulur ya da yayın esnasında yayını yapan kullanıcının reklamını yaptığı bir ürün veya hizmet ile duygusal bir bağ kurabilir. Bazen yayını yapan kişi farkında olmadan ortamda bulunan ürünü veya hizmeti hedef kitleyle tanıştırabilmektedir. Ayrıca markalar doğrudan canlı yayın uygulamaları sayesinde müşterilerin sorularını cevaplayabilmekte, üretim süreçlerini göstermekte, ürün ve hizmet tanıtımı yapmakta ve çeşitli etkinliklerini paylaşmaktadır (Recelar,2017). Bu da markalarını kullanıcılara daha iyi tanitabilmekte ve merak edilen sorulara anında cevap verebilme imkanı tanımaktadır.

\section{Araştırmanın Amacı}

Hayatın her alanında kendini gösteren sosyal medya yalnızca sosyal yaşam alanlarını değil iş alanlarını da etkilemekte ve bu alanlara yön vermektedir. Sosyal ağlar her gecen gün yeni özellikler kazanmaktadır ve bunlardan biri canlı yayınlardır. Kullanımı hızla artan ve çabuk benimsenen canlı yayınların gelecekte de önemli yere sahip olacağı düşünülmektedir. Şuan için yeni sayılabilecek canlı yayınlar ile ilgili çalışmalar sınırlı sayıdadır.

Bu çalışmanın amacı son dönemde sosyal medya platformlarında etkin bir şekilde kullanılan canlı yayınların hangi amaçlarla, ne sıklıkta kullanıldığını görmek ve yayınların ürün reklam, tanıtım vb. pazarlama faaliyetlerinin işlenip işlenmediğini analiz etmektir.

\section{Araştırmanın Metodolojisi}

Araştırma kapsamında Periscope adlı sosyal medya uygulamasından belli sayıda izlemeler yaparak veriler toplanmıştır. Bu kapsamda izlemeler Periscope (Scope) programinda 2 hafta boyunca belli saatlerde, günlük 10 izleme olarak gerçekleştirilmiştir. Toplamda 280 izleme incelenmiştir. 2015 ve 2017 yılında yapılan iki ayrı uygulama bulunmaktadır ve değerlendirmeler bu iki yıl üzerinden yapılmıştır. Yapılan izlemelerde, yayınların yapıldığı yıla, 
saate, güne, sıralamasına, yayını yapan kişinin cinsiyetine, izleyici sayısına, konusuna, yayını yapan kişinin kendini gösterip göstermediğine, mekanı gösterip göstermediğine, ürün reklam ve tanıtım olup olmadığına, eğer reklam ve tanıtım varsa dolaylı veya doğrudan olduğuna, yorumların içeriğine, etik açıdan sorun olup olmadığına, ihlal edilen şeyin ne olduğuna ve yayını yapanın yönlendirme talebinin olup olmadığına değinilmiştir.

Araştırma kapsamında Microsoft Excel programı ile rastgele üretilen tarih ve saatler oluşturularak herhangi bir kitle ayrımı yapılmadan 2 hafta boyunca belirlenen gün ve saatte Periscope (Scope) adlı uygulamadan yapılan canlı yayınlar izlenmiştir. Günlük 10 yayın olmak üzere 2015 yılı için iki haftalık izlemede toplam 1402017 yılı için iki haftalık izlemede toplam 140 olmak üzere toplamda 280 izleme yapılmıştır. Yapılan izlemelerde ülke ve kişilerin sosyo-demografik özellikleri açısından ayrım yapılmamıştır.

\section{Araştırmanın Bulguları ve Değerlendirilmesi}

Araştırma verileri Microsoft Excel adlı programda belli kategorilere göre kodlanmıștır ve daha sonra SPSS adlı program kullanılarak analiz edilmiştir. T-Test, ANOVA ve Post Hoc Test (Tukey ve LSD) analizleri yapılmıștır.

Tablo 2. Yıllar itibariyle izleyici sayısındaki artış

\begin{tabular}{llllll}
\hline & Yil & $\mathbf{N}$ & Ortalama & Std. Sapma & Std.Hata \\
\hline \multirow{2}{*}{ İzleyici Sayısı } & 2015 & 140 & 59.1500 & 119.50112 & 10.09969 \\
\cline { 2 - 6 } & 2017 & 139 & 179.6043 & 624.47415 & 52.96721 \\
\hline
\end{tabular}

Canlı yayın uygulamalarının çeşitlenmesi ve bilinirliğinin artmasıyla birlikte yıllar itibariyle izleyici sayısında belirgin bir artış görülmektedir (Tablo 2). 2015 yılında incelenen izlemelerde 140 izleme yapılmış bu izlemelerde izleyici ortalaması 59,15 olmuştur. 2017 yılında yapılan 139 izlemede izleyici ortalaması 179.60 olmuştur.

Tablo 3. Yıllara göre izleyici sayısı farklılıkları

\begin{tabular}{lllllll}
\hline & & \multicolumn{5}{c}{ t-test } \\
\cline { 3 - 6 } & & $\mathbf{F}$ & Sig. & $\mathbf{t}$ & $\mathbf{d f}$ & Sig. \\
\hline İzleyici & Varsayılan varyans eşitliği & 10.257 & 0.002 & -2.241 & 277 & 0.026 \\
\cline { 2 - 7 } Sayıs1 & Varsayllan varyans eşitsizliği & & & -2.234 & 148.023 & 0.027 \\
\hline
\end{tabular}


Tablo 3' de izleyici sayısı ve yıl analizlerine bakıldığında Sig.(2-tailed) değerinin 0.027 olduğu yani değişkenler arasında anlamlı farklılık bulunduğu görülmektedir.

Araştırma kapsamında hangi kişi veya gurubun daha fazla izlendiğini tespit etmek amacıyla canlı yayın yapanlar guruplara ayrılmıştır. Canlı yayını yapan tek erkekler 1, tek kadınlar 2 , bir veya daha fazla erkekten oluşan erkek grup 3 , bir veya daha fazla kadından oluşan kadın grup 4 ve erkek kadın karışık grup 5 olarak gösterilmiştir.

Tablo-4'e göre kadınların tek başlarına yaptıkları yayınların izlenme sayılarının tek başına yayın yapan erkeklere göre daha fazla olduğu $(p<0.05)$ görülmektedir. Ayrıca tek başına yayın yapan kadınların izleyici sayılarının grup halinde yayın yapan hem erkeklerden $(p=0.05)$ hem de kadınlardan $(\mathrm{p}<0.1)$ daha fazla olduğu ortaya çıkarılmıştır.

Tablo 4. İzleyici Sayısı - Cinsiyet Karşılaştırmaları Post Hoc Test Sonuçlan

\begin{tabular}{|c|c|c|c|c|c|c|}
\hline \multirow{2}{*}{$\begin{array}{l}\text { Canlı } \\
\text { yayın yapan } \\
\end{array}$} & \multirow{2}{*}{$\begin{array}{l}\text { Canlı } \\
\text { yayın yapan }\end{array}$} & \multirow{2}{*}{$\begin{array}{l}\text { Ortalama } \\
\text { Fark.(I-J) } \\
\end{array}$} & \multirow{2}{*}{$\begin{array}{l}\text { Std. } \\
\text { Hata }\end{array}$} & \multirow{2}{*}{ Sig. } & \multicolumn{2}{|c|}{ 95\% Güven Aralığ1 } \\
\hline & & & & & Alt Sinir & Üst Sinır \\
\hline \multirow{5}{*}{ Tek Kadın } & Kişi yok & $196.57843^{*}$ & 85.52526 & 0.022 & 28.2083 & 364.9486 \\
\hline & Tek Erkek & $155.17492^{*}$ & 75.64811 & 0.041 & 6.2495 & 304.1003 \\
\hline & Erkek Grup & $250.09510^{*}$ & 118.47391 & 0.036 & 16.8603 & 483.3299 \\
\hline & Kadin Grup & 215.13399 & 123.11100 & 0.082 & -27.2297 & 457.4976 \\
\hline & Karışık Grup & 180.27451 & 125.75885 & 0.153 & -67.3019 & 427.8509 \\
\hline
\end{tabular}

Tablo 5. Kadın-Erkek izlenme oranları

\begin{tabular}{llllll}
\hline & Canlı Yayın yapan & $\mathbf{N}$ & Ortalama & Std. Sapma & $\begin{array}{l}\text { Std. Hata } \\
\text { Ortalama }\end{array}$ \\
\hline İzleyici sayısı & Erkek & 114 & 111.5702 & 229.47732 & 21.49252 \\
\cline { 2 - 6 } & Kadın & 51 & 266.7451 & 979.99483 & 137.22672 \\
\hline
\end{tabular}

Sadece tek erkek ve tek kadın izlemeler dikkate alındığında kadınların izleyici sayısının (266.74) erkeklerden (111.57) daha fazla olduğu görülmektedir.

Tablo 6'ya bakıldığında canlı yayın yapan tek erkek ve tek kadın izlenme oranlarında anlamlı bir farklılık (Sig: 0.111) görülmemiştir. Ancak Tablo 5 ve şekil 1'e baktığımızda tek kadınların (2) tek erkekler (1) ve diğer gruplara göre daha çok izleyici sayısına sahip olduğu görülmektedir. 
Tablo 6. Kadın-Erkek izlenme farklılıkları

\begin{tabular}{lllllll}
\hline & & \multicolumn{5}{c}{ t-test } \\
\cline { 3 - 7 } & & $\mathbf{F}$ & Sig. & $\mathbf{t}$ & $\mathbf{d f}$ & Sig. \\
\hline İzleyici & Varsayılan varyans eşitliği & 4.571 & 0.034 & -1.601 & 163 & 0.111 \\
\cline { 4 - 7 } Sayıs1 & Varsayılan varyans eşitsizliği & & & -1.117 & 52.469 & 0.269 \\
\hline
\end{tabular}

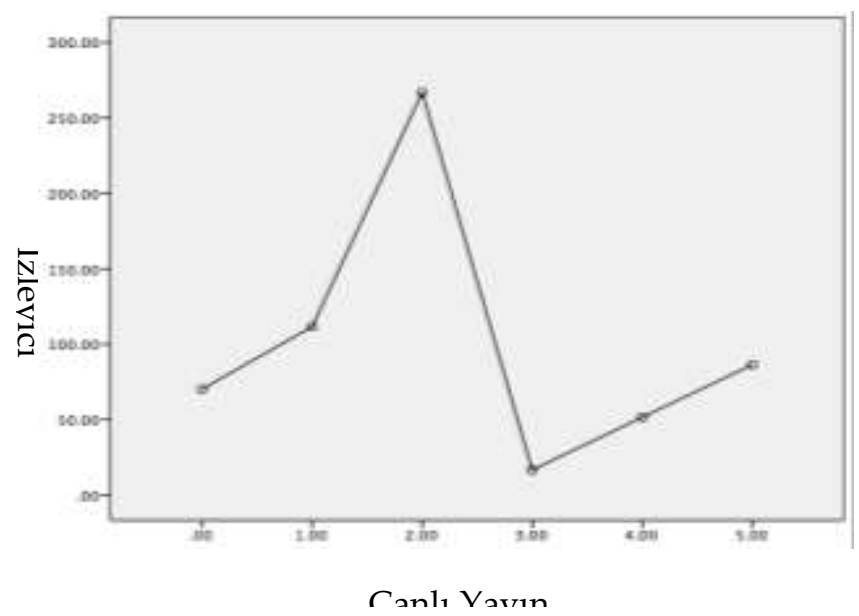

Şekil 1. Canlı yayın izleyici sayısı grafiği

Canlı yayın izlemelerinde üst sıralarda yer alan yayınların alt sıralarda yer alan yayınlara nazaran daha fazla izlendiği tespit edilmiştir. Özellikle uygulama yazılımında ilk üç sıradaki yayınların ebat olarak alt sıralarda yer alan yayınlara nazaran büyük olmaları bu yayınları daha görünür kılmış ve daha ilgi çekici hale getirmiştir.

Tablo 7. İzleyici sayısı-Stralama oranları

\begin{tabular}{llllll}
\hline & Siralama & $\mathbf{N}$ & Ortalama & Std. Sapma & Std. Hata Ortalama \\
\hline \multirow{2}{*}{ İzleyici sayısı } & Üst Sira & 84 & 252.7381 & 772.95203 & 84.33598 \\
\cline { 2 - 6 } & Alt Sira & 196 & 61.4031 & 161.42327 & 11.53023 \\
\hline
\end{tabular}

Araştırmada yapılan yayınlarından üst sırada olanlar (ilk üç, yayın) 1, alt sırada olan yayınlar ise 2 olarak kodlanmıştır.

Tablo 8. İzleyici sayısı-Sıralama farklılıkları

\begin{tabular}{lllllll}
\hline & & \multicolumn{5}{c}{ t-test } \\
\cline { 3 - 7 } & & $\mathbf{F}$ & Sig. & $\mathbf{t}$ & df & Sig. \\
\hline İzleyici & Varsayılan varyans eşitliği & 10.943 & 0.001 & 3.309 & 278 & 0.001 \\
\cline { 2 - 7 } Sayı1 & Varsayllan varyans eşitsizliği & & & 2.248 & 86.119 & 0.027 \\
\hline
\end{tabular}




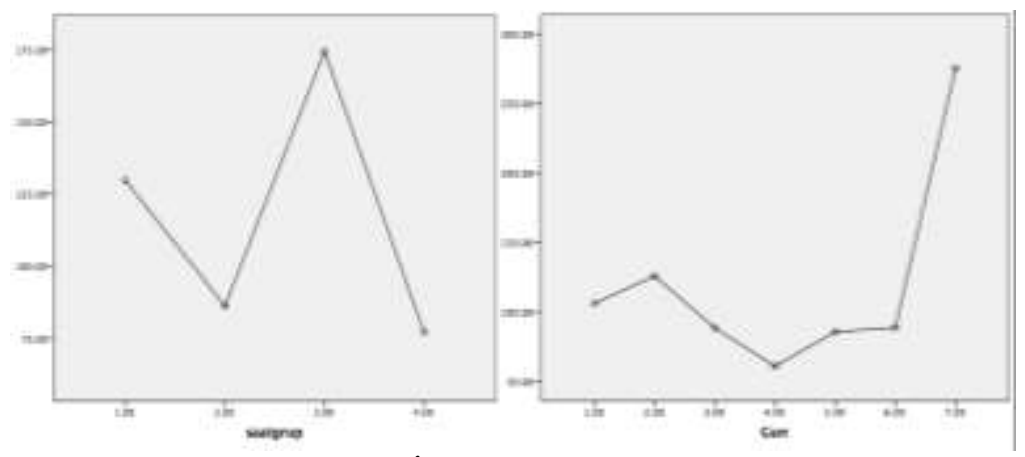

Şekil 2. İzleyici sayısı-Gün/saat grafiği

İzleyici sayısı ve sıralamaya baktığımızda sig(2-tailed) değeri 0.027 dir. Yani değişkenler arasında anlamlı farklılık bulunmaktadır. Bu sonuca göre üst sıralardaki yayınların izleyici sayısının (252.7381) alt sıradaki yayınların izleyici sayılarından (61.4031) daha çok olduğu görülmektedir.

İzleyici sayısı ve gün açısından incelendiğinde izleyici sayısının en yoğun olduğu günün Pazar (7) (275.5250) günü olduğu görülmektedir. Diğer günlere bakıldığında ise yoğunluğun Salı(2), Pazartesi(1), Çarşamba(3), Cumartesi(6), Cuma(5) ve Perşembe(4) şeklinde olduğu görülmektedir. İzleyicilerin hangi saat aralıklarında canlı yayınları izledikleri incelendiğinde, izleyici sayısının en çok 12.00-18.00 $(174,3300)$ saatleri arasında olduğu görülmektedir. Daha sonra 00.00-06.00，06.00-12.00 ve 18.00-24.00 saatleri şeklinde sıralanmaktadır.

Tablo 9. Ürün ve Hizmet tanıtımı

\begin{tabular}{llllll}
\hline & & Frekans & Yüzde & Geçerli Yüzde & Toplam Yüzde \\
\hline \multirow{4}{*}{ Yüzde } & Reklam Yok & 151 & 53.9 & 53.9 & 53.9 \\
\cline { 2 - 6 } & Bilinçli Reklam & 21 & 7.5 & 7.5 & 61.4 \\
\cline { 2 - 6 } & Dolaylı Reklam & 108 & 38.6 & 38.6 & 100.0 \\
\cline { 2 - 6 } & Total & 280 & 100.0 & 100.0 & \\
\hline
\end{tabular}

Ürün ve hizmet tanıtımı açısından canlı yayınlar incelediğimizde toplam yayın içinde 151 yayında (\%53.9) hiç reklam ve tanıtım bulunmadığı 129 yayında (\%46.1) ise ürün ve hizmet tanıtımının yer aldığ görülmektedir. Reklam bulunan yayınlarda yayınların \%7,5 inde yayıncı direkt olarak bir ürün veya hizmeti tanıtmakta, \%38.6'sı ise ortamda dolaylı olarak yapılan reklamları içermektedir. 
Canlı yayınların içerikleri incelendiğinde yapılan yayınların genellikle bireylerin veya gurupların kendilerini göstererek yaptıkları, bireysel çekimlerin \%43.52 oranla toplam yayınlar içindeki oranının en yüksek olduğu gözlemlenmiştir. Bireysel çekimleri ,\%20,86 oranla Eğlence içerikli yayınlar izlemektedir. Daha sonra Gezinti \% 10,43 , Manzara \%5,39 , Spor \%5,39 , Medya \%3,95, Okul ortamı \% 3,95, Dini içerikli yayınlar \%2,51, Marka Tanıtım $\% 2,15$, Siyasi içerikli yayınlar $\% 1,43$ ve Eğitim içerikli yayınlar $\% 0,35$ şeklinde sıralanmaktadır.

\section{Sonuç ve Değerlendirme}

Hayatın her alanına işleyen sosyal medya ağları sürekli olarak güncellenip geliştirilmekte ve yeni özellikler eklenmektedir. Penetrasyon oranın çok kısa olduğu canlı yayın uygulamaları da bunlardan biridir. Bu uygulama ile kişiler istedikleri an istedikleri yerde canlı yayın yapabilmektedirler. Canlı yayınlar sadece kişiler tarafından değil kurum ve işletmeler tarafından da kullanılmaktadır.

Canlı yayın platformları arasında en popüler olanlardan biri periscope (scope)dur. Periscopla birlikte facebook instagram ve diğer sosyal medya platformlarının da bu özelliği kullanmaya başlaması ile birlikte canlı yayınlar daha popüler hale gelmiştir. Canlı yayınlar birçok alanda kullanıldığı gibi reklam, tanıtım, medya ve eğlence gibi çeşitli amaçlarla da kullanılmaktadır. Bu çalışma da Periscope adlı canlı yayın uygulaması ile yaptığımız izlemeler değerlendirilmiştir. Toplamda 280 izleme yapılmıştır.

İzlemeler sonucunda yayını yapan birey yada gurup açısından değerlendirme yapıldığında kadınların erkeklere göre daha çok izleyicisinin bulunduğu görülmektedir. Bu platformları reklam mecrası olarak kullanmak isteyen birey ve işletmeler için kadınların yapmış olduğu yayınlara odaklanmak daha yerinde bir tercih olacaktır.

Yayınların yılına bakıldığında 2015 yılının izleyici ortalaması 59,15 iken 2017 yılının izleyici ortalaması 179,60'dır. Yani 2017 yılında yapılan yayınlar daha çok kişi tarafından izlenmektedir. Bu sayının yıllar içerisinde düzenli olarak artacağı görülmektedir. Bu da canlı yayın platformlarının reklam faaliyetleri için önemli bir alan olarak öne çkaracaktır.

Yayın sıralamaları incelendiğinde üst sıradaki yayınların(ilk üç yayın) alt sıradaki yayınlara göre daha çok izlendiği görülmüştür. Bu durumda rek- 
lam vermek isteyen firmaların özellikle sponsor veya popüler yayın olarak üst sıralarda yer alan yayınlara reklam vermeleri daha uygun görülebilir.

Yayınların gün ve saatleri açısından incelendiğinde Pazar günü izleyici sayısı açısından en yoğun gün olduğu, en çok izleyicinin 12.00-18.00 saatleri arasında olduğu görülmüştür. 280 yayının \%53.9 'unda reklam bulunmazken \%46.1 inde reklam ve tanitım bulunmaktadır. Bu reklam ve tanitımlar bazen yayıncının bizzat kendi tarafindan yapilırken, bazen de yayıncının bulunduğu ortamda yayın alanının içerisinde yer almaktadır. Yayınların konusu açısından değerlendirildiğinde en çok bireysel çekimlerin ve eğlence içerikli çekimlerin yapıldığ görülmektedir. Önümüzdeki dönemlerde büyük sosyal medya platformlarının kullanıcılarına canlı yayın imkanı sunması bu mecraları daha da hareketlendirecektir. Özellikle ünlüler, sanatçılar, tanınmış kişiler takipçilerine bu ortamlardan daha sık paylaşımlar yapacaktır. Özellikle firmaların bu noktada takipçi sayısı fazla olan kişilere çeşitli imkanlar sağlayarak ürün ve hizmet reklamı yaptırmaları son dönemde daha sık karşılaşacağımız bir durum olarak görülecektir. 


\title{
EXTENDED ABSTRACT
}

\section{Product / Brand Placements on Live Broadcasting Applications}

\author{
İkram Daştan \\ * \\ Yalova University
}

New social media tools with their new features have been appearing in the internet day by day. One of the most important steps in these fields is the feature of being able to broadcast an online live feed spontaneously (Bajarin 2015). Periscope, founded by Kavyon Beykpour and Joe Bernstain in 2014, became the most popular and growing real-time live stream application. The popularity and features of Periscope, which started its journey with the slogan of exploring the world in real time through the eyes of others, drew the attention of important agents in the social media industry and finally Twitter bought Periscope. The idea beyond the foundation of Periscope emerged with the desire of Kavyon Beykpour's real-time live streaming of Gezi Events occured in Taksim in 2013 and people's being able to watch these broadcasts live. The aim of Periscope which is parallel to Beykpour's idea has been exploring the world through the eyes of others (Periscope, 2015). Although real time live stream platforms are recently new; celebrities, politicians, bloggers and companies have started to use these fields very actively (Reilly, 2015; Bajarin, 2015). As live experience is seen more authentic especially by young generations, it has caused its spreading faster among young generations (Pophal, 2016). Moreover, bloggers work effectively and efficiently by using Periscope. Travel bloggers have started to broadcast real time live feed from the places they travel.

Sharing one's experience, is not a new concept for social media apps. Real-time video streaming tools that enable special features, are accepted as one of the most promising new media communication tools. Live-streamers provide a real-time interactive experience between the content creator and the consumer (Sjoblom ve Hamari, 2016). When looked at from this perspective, marketers and advertisers are faced with a steadily changing, complicated environment (Philip ve Noble, 2007). Live-stream fields are increasing 
in a fast pace for the sake of consumer interaction. In the digital sector, it is foreseen that expenditures directed at live-streaming, video marketing and video advertising until the year 2019 will exceed 14 million dollars annually (Gehlen, 2015; Facebook Live İstatistikler, 2017). It is stated by researchers that users are more intrigued by mobile and video contents rather than textual content. In the annual report of the social media advertisement sector, it is found that $60 \%$ of advertisers use videos, $75 \%$ of advertisers want to acquire more knowledge about the use of videos in advertisement and plan on increasing their usage of videos (Stelzner, 2016).

The aim of this study is to see for what purposes and how often live streaming is recently used effectively in the social media platforms and to analyze whether product advertisement, promotion and marketing activities of broadcasts etc. are processed.

Within the scope of the research, data was collected by monitoring a certain amount through the social media application called Periscope. In this context, monitorings were conducted through Periscope (Scope) programme, daily 10 monitorings, at certain times during two weeks. 280 monitorings were analyzed in total. There are two different implementations conducted in 2015 and 2017 and assessments were made over these two years. In the conducted monitorings, the year that the broadcasts were published in, the hour, the day, the ranking, the gender of the person who has conducted the broadcast, the number of viewers, the topic, whether the broadcaster shows himself/herself, whether he/she shows the environment, whether there is product advertising \& promotion, if there is advertising and promotion whether it is direct or indirect, the content of comments, whether there is a problem from an ethical perspective, what is the thing that is being violated and whether the broadcaster has a referral request or not are mentioned.

Research data was coded in regard to certain categories in the programme named Microsoft Excel and then was analyzed by using the programme named SPSS. T-Test, ANOVA and Post Hoc Test (Tukey ve LSD) analyses were made.

As a result of the monitorings, when evaluated in terms of the person or group that is broadcasting it is observed that females have more viewers than males. It will be a more suitable preference to focus on the broadcasts 
of the female for the person and the businesses who want to use these platforms as advertisement channel.

When looked at the years of the broadcasts, the average viewers of the year 2015 is 56,15 whereas the average viewers of the year 2017 is 179,60 . It means that the broadcasts conducted in 2017 are watched more. It is foreseen that this number will increase regularly in years. And this will become prominent as an important field for the live streaming platforms.

When the ranks of the broadcasts are analyzed, the broadcasts on the top (first three broadcasts) are watched more than the broadcasts at the bottom. In that circumstance, it can be found more acceptable for the companies that want to give advertisement to the broadcasts at the top ranks especially as a sponsored and popular broadcast. When the broadcasts are analyzed in terms of day and time, it has been seen that Sunday is the busiest day in terms of viewer number and the most viewers are between $12.00-18.00 \mathrm{pm}$. In \%53.9 of 280 broadcasts there aren't any advertisements whereas in \%46.1 there are advertisements and promotions. These advertisements and promotions are sometimes conducted by the live-streamer himself/herself and sometimes they are in the environment of the live-streamer.

When evaluated in terms of the topics of the broadcasts, it is seen that individual footages and fun thematic footages are conducted most. In the upcoming periods, big social media platforms' providing an opportunity of live feed broadcasts to their users will activate these fields more. Especially celebrities, artists, well-known people will make more sharing from that environment to their followers. It will be seen as more often encountered situation in recent periods that companies, especially at this point, will provide various opportunities to people with a high number of followers for product and service advertisement.

\section{Kaynakça / References}

AdWeek. (2015, 12 January). Infographic: Who's really using Facebook, Twitter, Pinterest, Tumblr and Instagram in 2015. Retrieved June 15, 2015, from http://www.adweek.com/news/advertising-branding/new-socialstratosphere-who-using-facebook-twitter-pinterest-tumblr-andinstagram-2015-and-beyond-1622 
Anderson, K. E. (2017). Getting acquainted with social networks and apps: periscope up! Broadcasting via live streaming. Library Hi Tech News, 34(3), $16-20$.

Bae, S. ve Lee, T. (2011), Product type and consumers perception of online consumer reviews. Electronic Markets, Heidelberg, 21(4), 255-266.

Bajarin, T. (2015). How Taylor Swift saved Apple music. Time.

Bazarova, N. N. ve Choi, Y. H. (2014). Self-disclosure in social media: Extending the functional approach to disclosure motivations and characteristics on social network sites. Journal of Communication, 64(4), 635-657.

Dunne, A., Lawlor, M.A.ve Rowley, J. (2010). Young people's use of online social networking sites - A uses and gratifications perspective. Journal of Research in Interactive Marketing, 1(4), 46-58.

Facebook Live Statistics (2017). Facebook video statistics. http://mediakix.com/2016/08/facebook-video-statistics-everyone-needsknow/\#gs.MGLVVBs accessed 15 May 2017.

Gehlen, S. (2015). Experts agree: Live streaming video for brands is one of 2016's biggest marketing trends [Blog Yazıs1]. Brand Live, www.yourbrandlive.com/blog/live-streaming-video-marketing- trends2016 accessed 7 July 2016

Goodchild, M. F. (2007). in the World of Web 2.0. International Journal, 2(2), 27-29. Haridakis, P. ve Hanson, G. (2009). Social interaction and co-viewing with YouTube: Blending mass communication reception and social connection. Journal of Broadcasting \& Electronic Media, 53(2), 317-335.

Kaplan, A. M., ve Haenlein, M. (2010). Users of the world, unite! The challenges and opportunities of Social Media. Business horizons, 53(1), 59-68.

Katz, E., Blumler, J. G., ve Gurevitch, M. (1974). The uses of mass communications: Current perspectives on gratifications research. Beverly Hills.

Livingstone, S. (2005) On the Relation Between Audiences and Publics: why audience and public? London: LSE Research Online, Cilt(Sayı), xxx-xxx. Xx.xx.xxxx tarihinde http://eprints.lse.ac.uk/archive/00000437_adresinden erişilmiştir.

Luo, X. (2002). Uses and gratifications theory and e-consumer behaviors: a structural equation modeling study. Journal of Interactive advertising, 2(2), 3441.

Malik, O. (2015), Periscope, Snapchat, Meerkat: We'll do it live", FastCompany, available at: www.fastcompany.com/3045472/technovore/well-do-it-live accessed on 1 March 2017. 
Mangold, W. G., ve Faulds, D. J. (2009). Social media: The new hybrid element of the promotion mix. Business horizons, 52(4), 357-365.

Newhagen, J. E., \& Rafaeli, S. (1996). Why communication researchers should study the Internet: A dialogue. Journal of Computer-Mediated Communication, 1(4), xxx-xxx.

O'Reilly, T., (2005). What Is Web 2.0," [Blog Yazısı], O'Reilly, retrieved in 15th April 2011 from http://www.oreillynet.com/pub/a/oreilly/tim/news/2005/09/30/what-isweb-20.html

Periscope (2015). Başlık. 21.05.2017. https://www.periscope.tv/about

Phillips, J., ve Noble, S. M. (2007). Simply captivating: Understanding consumers' attitudes toward the cinema as an advertising medium. Journal of Advertising, 36(1), 81-94.

Pophal, L. (2016), New options and opportunities with live streaming video, EContent, available at: www.econtentmag.com/Articles/News/NewsFeature/New-Options-and-Opportunities-With-Live- Streaming-Video114164.htm (accessed 22 February 2017).

Robinson, J.D., James, L.R., Thomas, A.C.I. ve Blandford, K. (2007). ABD Patenti No. 7,168,051 . Washington, DC: ABD Patent ve Marka Ofisi.

Roettgers, J. (2015), Periscope has been used for 200 million broadcasts, 100 Million since January alone, Variety, available at: http://variety.com/2016/digital/news/periscope-200-million-broadcasts1201740099/ accessed 4 March 2017).

Rubin, A. M. (1994). Media uses and effects: A uses-and-gratifications perspective.

Rubin, A. M. (2009). Uses-and-gratifications perspective on media effects. In Media effects (p. 181-200). Routledge.

Savage, J. (2015), Top 5 video marketing trends for 2016. Social Media Today, available at: www.socialmediatoday.com/marketing/top-5-videomarketing-trends-2016-infographic accessed 9 March 2017.

Savage, J. (2016), available at: www.socialmediatoday.com/marketing/top-5facebook-video-statistics-2016-infographic accessed 3 March 2017.

Sjoblom, M. and Hamari, J. (2016), Why do people watch others play video games? An empirical study on the motivations of twitch users, Computers in Human Behavior, Cilt(Say1), 1-12. available at: http://dx.doi.org/10.1016/j.chb.2016.10.019 accessed 1 June 2017. 
Socialbakers (2018). Başlık.: 01.05.2018 tarihinde http://www.socialbakers.com/statistics/twitter/_adresinden erişilmiştir.

Spangler, T. (2016), Election live-streaming video of presidential race breaks internet record, Variety, November. 9 2016, available at: http://variety.com/2016/digital/news/election-2016-live-streamingvideo-presidential-internet-record-1201914039/ accessed 15 January 2017.

Stelzner, M. (2016), The 2016 social media marketing industry report: how marketers are using social media to grow their businesses, Social Media Examiner, Cilt(Say1), 1-56.

Todd, P. R., ve Melancon, J. (2018). Gender and live-streaming: source credibility and motivation. Journal of Research in Interactive Marketing, 12(1), 79-93.

Urista, M. A., Dong, Q., ve Day, K. D. (2009). Explaining why young adults use MySpace and Facebook through uses and gratifications theory. Human Communication, 12(2), 215-229.

Papuççiyan, A. (2018). Facebook aylık 2 milyar kullanıcı barajını aştı. [Blog Yazıs1], Webrazzi, 01.05.2018 tarihinde https://webrazzi.com/2017/06/28/facebook-2-milyar/_adresinden erişilmiştir.

\section{Kaynakça Bilgisi / Citation Information}

Daştan, İ. (2019). Canlı yayın platformlarında ürün marka uygulamaları. OPUS-Uluslararası Toplum Araştırmaları Dergisi, 16(28), 1396-1415. DOI: $10.26466 /$ opus.738697 